\title{
Effects of soil drying and wetting-drying cycles on the availability of heavy metals and their relationship to dissolved organic matter
}

\author{
Zhu Li • Longhua Wu • Hao Zhang • Yongming Luo • \\ Peter Christie
}

Received: 18 October 2014 / Accepted: 8 February 2015 /Published online: 8 March 2015

(C) Springer-Verlag Berlin Heidelberg 2015

\begin{abstract}
Purpose Variation in soil moisture content can change metal availability. However, the effects of soil drying during wetting-drying cycles on metal availability have been little investigated. Metal availability to an imposed sink can be assessed by the diffusive gradients in thin film (DGT) technique. The purpose of this study was therefore to investigate the effects of the soil drying processes and previous soil moisture contents on metal availability using DGT.

Materials and methods Two metal-polluted agricultural soils with contrasting $\mathrm{pH}$ (one acid and one calcareous) were collected from agricultural fields and were repeatedly phytoextracted with a $\mathrm{Zn} / \mathrm{Cd}$ hyperaccumulator. Both soils, with and without phytoextraction, were subjected to two soil drying processes, i.e. drying from flooded conditions to $50 \%$ maximum water holding capacity (WHC) and drying from 100 to $30 \%$ WHC. Changes in metal availability induced by changing soil water moisture were examined using DGT.
\end{abstract}

Responsible editor: Yong Sik Ok

Electronic supplementary material The online version of this article (doi:10.1007/s11368-015-1090-x) contains supplementary material, which is available to authorized users.

Z. Li $\cdot$ L. Wu $(\bowtie) \cdot$ Y. Luo $\cdot$ P. Christie

Key Laboratory of Soil Environment and Pollution Remediation, Institute of Soil Science, Chinese Academy of Sciences,

Nanjing 210008, China

e-mail:1hwu@issas.ac.cn

H. Zhang $(\bowtie)$

Lancaster Environment Centre, Lancaster University, Lancaster LA1 4YQ, UK

e-mail: h.zhang@lancaster.ac.uk

Y. Luo

Key Laboratory of Coastal Zone Environmental Processes, Yantai Institute of Coastal Zone Research, Chinese Academy of Sciences, Yantai 264003, China
Results and discussion In acid soils, the availability of cadmium (Cd), zinc ( $\mathrm{Zn})$ and nickel (Ni) (but not copper) increased with drying from saturation to $50 \%$ WHC. Drying soil from 100 to $30 \%$ WHC had weak or no significant effects on available metals. Availabilities of $\mathrm{Cd}, \mathrm{Ni}$ and $\mathrm{Zn}$ correlated well with available $\mathrm{Al}$ for both drying conditions. In calcareous soil, a decreasing trend of metal availability with soil drying from saturation to $50 \% \mathrm{WHC}$ or from 100 to $30 \% \mathrm{WHC}$ was found. Soils were also subjected to different wetting-drying cycles prior to drying. In acid soil, available copper $(\mathrm{Cu})$ was correlated with dissolved organic carbon (DOC). Available $\mathrm{Cd}, \mathrm{Ni}$ and $\mathrm{Zn}$ were correlated with available $\mathrm{Al}$ and increased with soil wetting-drying cycles in phytoextracted soil, but not in nonremediated soil. In calcareous soil, available $\mathrm{Cu}$ and $\mathrm{Ni}$ were correlated well with DOC and were higher with long dry periods. However, available $\mathrm{Cd}$ and $\mathrm{Zn}$ were lower in soils dried from the cycle of saturation to $50 \% \mathrm{WHC}$.

Conclusions The results indicate that soil water regimes can be manipulated to alleviate soil metal availability, but they must be tailored to individual metals and different soil types, and soil moisture content before drying should be considered when dried soils are used for evaluation of metal availability.

Keywords Diffusive gradients in thin films (DGT) $\cdot$ Metal availability $\cdot$ Remediation $\cdot$ Water management

\section{Introduction}

Agricultural, mining and industrial practices result in toxic metals entering and accumulating in soils (Arunakumara et al. 2012). The excess metal accumulated in soils has become a serious environmental problem and also a risk to human health via the food chain ( $\mathrm{Li}$ et al. 2014a). The environmental risk of metals in soils is more closely related to the 
available fractions than to the total amounts present. Most methods used to evaluate soil metal bioavailability, including extraction with chemical agents and isotope dilution, are based on equilibrium principles (Huang et al. 2011; Menzies et al. 2007). However, the uptake of metals by soil organisms and plants usually involves dynamic processes associated with uptake, a decrease in soil solution metal concentration and metal release from soil solids. The technique of diffusive gradients in thin films (DGT) mimics the dynamic process of uptake with associated release of metal from the solution and soil solids (Davison and Zhang 1994; Davison et al. 2000). This technique has been shown to be a good surrogate for soil metal availability to plants in many conditions (Tandy et al. 2011; Williams et al. 2012).

The metal distribution between the soil solid phase and the soil solution will affect soil metal availability and mobility. In turn, metal distribution is usually affected by soil physicochemical properties such as $\mathrm{pH}$, Eh, organic matter content, $\mathrm{Fe} / \mathrm{Al} / \mathrm{Mn}$ - (hydr)oxides and dissolved organic carbon (DOC) in the soil solution (de Vries et al. 2011; Groenenberg et al. 2010; Fest et al. 2008). Some of these properties can change with variation in soil moisture content and thus change soil metal availability (Cornu et al. 2007). Studies have shown that water management can change soil metal mobility and availability and thus manipulate metal accumulation in rice plants (Yang et al. 2009; Hu et al. 2013; Xu et al. 2013). However, the effects of soil drying during wetting-drying cycles on metal availability have received little consideration in these studies. Phytoextraction can change the chemical and biological properties of metal-contaminated soils (Jiang et al. 2010), and this can introduce different effects of water management practices on metal availability between soils with and without phytoextraction. In addition, repeated phytoextraction will decrease soil available metals and this is an important factor limiting successful phytoextraction (Blaylock et al. 1997). Whether or not soil water management can change metal availability of remediated contaminated soils with low metal availability remains to be determined. Moreover, soils are usually dried after field sampling and then used to evaluate metal availability and risk assessment. However, metal availability can be affected by differences in soil wetting-drying cycles preceding soil drying and different drying patterns (Tack et al. 2006; Shaheen et al. 2014a, b). The different effects on soil metal availability of previous soil moisture processes before drying and the duration of the drying period were further investigated in the present study using the DGT method which takes into consideration the soil solid phase metal supply to the soil solution.

Two metal-polluted soils with contrasting $\mathrm{pH}$ were collected from agricultural fields and were repeatedly phytoextracted with a zinc $(\mathrm{Zn})$ /cadmium $(\mathrm{Cd})$ hyperaccumulator. Both soils, with and without phytoextraction, were subjected to two soil drying processes. The DGT technique was used to discriminate changes in metal availability in different soil water regimes. The aims were to investigate the changes in soil metal availability during the two soil drying processes, i.e. drying from saturation (flooded conditions) to $50 \%$ maximum water holding capacity (WHC) and drying from 100 to $30 \%$ WHC, and the effects of different soil water moisture processes before drying on metal availability.

\section{Materials and methods}

\subsection{Soil properties}

Two top soils (depth $0-20 \mathrm{~cm}$ ) with different soil properties and metal pollution levels were collected from the field. One was an acid soil (HLD; Hapli-Ustic Agrosols) collected from an agricultural field at Huludao, Liaoning Province, northeast China, where the soil was polluted for many years by wastewater discharge from a zinc smelter. The other was a calcareous soil (ZJW; Stagnic Anthrosols) collected from a rice field at Zhujiawu, Zhejiang Province, southeast China. This area was polluted by a copper smelter for many years. The two contaminated soils were phytoextracted using the $\mathrm{Cd} / \mathrm{Zn}$ hyperaccumulator Sedum plumbizincicola for 3 years. After phytoremediation, both soils showed a manifest decrease in soil total $\mathrm{Cd}$ and $\mathrm{Zn}$ concentrations ( $\mathrm{Li}$ et al. 2014b). The contaminated soils (with and without phytoremediation), designated HLD-R, ZJW-R, HLD-NR and ZJW-NR, respectively, were subjected to different water regimes. All soils were air-dried, ground to pass a 1-mm nylon sieve and stored for $>6$ months before use.

Selected soil properties were determined. Soil $\mathrm{pH}$ was measured with a glass electrode at a soil/water ratio of 1:2.5. Soil organic carbon (OC) was determined by the Walkley-Black method. Soil cation exchange capacity (CEC) was determined by exchange with ammonium acetate $\left(1.0 \mathrm{~mol} \mathrm{~L}^{-1}, \mathrm{pH} 7.0\right)$ and titration with $\mathrm{HCl}\left(0.05 \mathrm{~mol} \mathrm{l}^{-1}\right)$. Soil total metals were determined by atomic absorption spectrophotometry (AAS) using a Varian SpectrAA 220FS, 220Z (Varian, Palo Alto, CA) after digestion of 0.1 -g samples with $10 \mathrm{ml}$ of $\mathrm{HCl}-$ $\mathrm{HNO}_{3}(1: 1, v / v)$. The results are shown in Table 1.

\subsection{Soil water regimes}

The original soils used in the experiment were already airdried, and therefore, soil pre-incubation was carried out before they were subjected to the different water treatments. The airdried soil samples were pre-incubated to equilibrate at $60 \%$ of maximum water holding capacity (WHC) for 7 days by weighing 21-g soil (oven-dried basis) into a PVC cup (37$\mathrm{mm}$ diameter and 60-mm high) and adjusting and maintaining the soil moisture daily by adding distilled water. The soil samples were then subjected to the different water regime treatments. 
Table 1 Selected soil properties and total metal concentrations

\begin{tabular}{|c|c|c|c|c|c|}
\hline \multirow{2}{*}{\multicolumn{2}{|c|}{ Soil property }} & \multicolumn{2}{|l|}{ HLD } & \multicolumn{2}{|l|}{ ZJW } \\
\hline & & NR & $\mathrm{R}$ & NR & $\mathrm{R}$ \\
\hline \multicolumn{2}{|l|}{ Sand (\%) } & 10.2 & - & 10.7 & - \\
\hline \multicolumn{2}{|l|}{ Silt (\%) } & 57.8 & - & 44.1 & - \\
\hline \multicolumn{2}{|l|}{ Clay (\%) } & 32.0 & - & 45.2 & - \\
\hline \multicolumn{2}{|l|}{$\mathrm{pH}\left(\right.$ in $\left.\mathrm{H}_{2} \mathrm{O}\right)$} & 4.77 & 4.71 & 7.14 & 7.72 \\
\hline \multicolumn{2}{|l|}{$\mathrm{OM}\left(\mathrm{g} \mathrm{kg}^{-1}\right)$} & 44.5 & 39.1 & 61.0 & 57.6 \\
\hline \multicolumn{2}{|c|}{$\mathrm{CEC}\left(\mathrm{cmol}_{(+)} \mathrm{kg}^{-1}\right)$} & 15.4 & - & 11.2 & - \\
\hline \multirow{2}{*}{$\begin{array}{l}\text { Total metal } \\
\qquad\left(\mathrm{mg} \mathrm{kg}^{-1}\right)\end{array}$} & $\mathrm{Zn}$ & $476 \pm 19$ & $229 \pm 12$ & $1201 \pm 15$ & $978 \pm 5$ \\
\hline & $\mathrm{Cd}$ & $8.68 \pm 0.14$ & $0.93 \pm 0.12$ & $2.28 \pm 0.10$ & $1.43 \pm 0.23$ \\
\hline
\end{tabular}

HLD and ZJW are two metal-contaminated agricultural soils

$R$ soil with phytoremediation, $N R$ soil without phytoremediation, $O M$ soil organic matter, $C E C$ soil cation exchange capacity

In the first regime, flooded to moderately wet drying $(\mathrm{F})$, the pre-incubated soils were submerged under a 2-cm depth of distilled water for $24 \mathrm{~h}$. The surface water (about $20 \mathrm{ml}$ ) was removed carefully by pipette, and the remaining soil was airdried to $50 \% \mathrm{WHC}$ at $19{ }^{\circ} \mathrm{C}$ for about 6 days. For this first cycle, the drying time was similar to that used by Zhang et al. (2008) under field conditions. In the case of samples subjected to a second cycle, the water removed by pipette in the first cycle was re-applied and the soil was kept submerged under $2 \mathrm{~cm}$ of water for $24 \mathrm{~h}$. The surface water was removed carefully and the soil was air-dried to $50 \%$ WHC. Within each cycle, soil samples at 125, 100 and $50 \%$ WHC moisture contents were used for analysis and were designated F1-125, F1-100 and F1-50 in the first cycle and F2-125, F2-100 and F2-50 in the second cycle. The metal concentrations in the water removed in each cycle are shown in Table S1 (Electronic Supplementary Material).

In the second regime, wet to severe drying $(\mathrm{M})$, the preincubated soils were adjusted to $100 \% \mathrm{WHC}$ and air-dried at room temperature $\left(19^{\circ} \mathrm{C}\right)$ to $30 \% \mathrm{WHC}$. This was the first cycle. Samples subjected to the second cycle were adjusted with distilled water to $100 \% \mathrm{WHC}$ and then air-dried. When two cycles were imposed, samples were analysed within each cycle at moisture contents of 80,50 and $30 \% \mathrm{WHC}$, designated M1-80, M1-50 and M1-30 in the first cycle and M2-80, M2-50 and M2-30 in the second cycle.

In the third regime, the soils were subjected to different wetting-drying cycles before drying. The air-dried samples from saturated conditions as in first regime (one or two cycles) were designated $\mathrm{F} 1$ or $\mathrm{F} 2$, respectively, and those from $100 \%$ $\mathrm{WHC}$ as in the second regime were designated $\mathrm{M} 1$ or $\mathrm{M} 2$ and the original soils (D: soils dried for $>6$ months, without wetting-drying cycle). Thus, the soil samples were subjected to different water treatments before drying.
All treatments were set up in triplicate, and for all soil samples, DGT devices were deployed within $3 \mathrm{~h}$ of the soil water contents reaching the set values. Table 2 shows the symbols used to denote the soil water regimes.

\subsection{The DGT devices and calculation of DGT concentrations}

Standard piston DGT devices (DGT Research, Lancaster, UK) were prepared with a diffusion layer overlying a Chelex (BioRad, Hercules, CA) resin layer. The diffusion layer comprised a 0.8 -mm-thick polyacrylamide gel with agarose derivative cross-linker and a 0.13 -mm-thick 0.45 - $\mu \mathrm{m}$-pore diameter cellulose nitrate filter.

The mass of metal accumulated in the resin gel layer of DGT can be obtained by

$M=C_{\mathrm{E}}\left(V_{\mathrm{HNO}_{3}}+V_{\mathrm{gel}}\right) / f_{e}$

where $C_{\mathrm{E}}$ is the concentration of metal in the $1 \mathrm{M} \mathrm{HNO}_{3}$ elution solution $\left(\mu \mathrm{g} \mathrm{L}^{-1}\right), V_{\mathrm{HNO}_{3}}$ is the volume of $\mathrm{HNO}_{3}$ added to the resin gel $(1 \mathrm{ml}), V_{\text {gel }}$ is the volume of the resin gel, typically $0.15 \mathrm{ml}$, and $f_{\mathrm{e}}$ is the elution factor for each metal, typically 0.8 .

The flux of metal measured by DGT $(F)$ and the concentration of metal at the interface of the DGT device and the soil $\left(C_{\mathrm{DGT}}\right)$ can be calculated using

$F=M /(\mathrm{t} A)$

$C_{\text {DGT }}=F \Delta g / D$

where $t$ is the deployment time (in seconds), $A$ is the exposure area, typically $2.54 \mathrm{~cm}^{2}, \Delta g$ is the thickness of the

Table 2 Symbols used in each water regime

\begin{tabular}{|c|c|c|c|c|c|c|}
\hline \multirow{2}{*}{$\begin{array}{l}\text { First regime } \\
\text { Water content } \\
\quad(\% \mathrm{WHC})\end{array}$} & \multicolumn{3}{|c|}{$\begin{array}{l}\text { First cycle of flooded to } \\
\text { moderately wet drying }\end{array}$} & \multicolumn{3}{|c|}{$\begin{array}{l}\text { Second cycle of flooded to } \\
\text { moderately wet drying }\end{array}$} \\
\hline & 125 & 100 & 50 & 125 & 100 & 50 \\
\hline Symbols & F1-125 & F1-100 & $\mathrm{F} 1-50$ & F2-125 & F2-100 & $\mathrm{F} 2-50$ \\
\hline Second regime & \multicolumn{3}{|c|}{$\begin{array}{l}\text { First cycle of wet to } \\
\text { severe drying }\end{array}$} & \multicolumn{3}{|c|}{$\begin{array}{l}\text { Second cycle of wet to } \\
\text { severe drying }\end{array}$} \\
\hline $\begin{array}{c}\text { Water content } \\
(\% \text { WHC })\end{array}$ & 80 & 50 & 30 & 80 & 50 & 30 \\
\hline Symbols & M1-80 & M1-50 & M1-30 & M2-80 & M2-50 & M2-30 \\
\hline Third regime & \multicolumn{2}{|c|}{$\begin{array}{l}\text { Dried from } \\
\text { flooded }\end{array}$} & \multicolumn{2}{|c|}{$\begin{array}{l}\text { Dried from } \\
100 \% \mathrm{WHC}\end{array}$} & \multicolumn{2}{|c|}{$\begin{array}{l}\text { Prolonged dry } \\
\text { period }\end{array}$} \\
\hline Cycles & One & Two & One & Two & None & \\
\hline Symbols & F1 & $\mathrm{F} 2$ & M1 & M2 & D & \\
\hline
\end{tabular}

WHC maximum water holding capacity 
diffusive gel $(0.08 \mathrm{~cm})$ plus the thickness of the filter membrane $(0.014 \mathrm{~cm})$, and $D$ is the diffusion coefficient of metal in the gel.

\subsection{The DGT deployment}

In water regimes 1 and 2, soils with moisture content of at least $100 \%$ WHC were used for DGT deployment; otherwise, the soil water content was adjusted to $100 \%$ WHC with deionized water. In regime 3 , the air-dried soil was firstly wetted to $60 \%$ WHC by adding deionized water to equilibrate for 2 days. Soil moisture content was then adjusted to $100 \%$ WHC with deionized water and equilibrated for one more day.

For DGT deployment, all soil samples were mixed thoroughly using a plastic spatula until a smooth paste was formed. The DGT devices were carefully placed on the soil paste with slight pressure to ensure complete contact between the filter membrane of the device and the soil. They were deployed on the acid soils (HLD-NR and HLD-R) for $16 \mathrm{~h}$ and on the calcareous soils (ZJW-NR and ZJW-R with lower availability of most metals) for $24 \mathrm{~h}$. During the deployment, the temperatures were within the range of $18-20^{\circ} \mathrm{C}$, and an average of $19^{\circ} \mathrm{C}$ was used in the calculation. On retrieval, the surfaces of the DGT devices were jet-washed with deionized water to remove soil particles and then disassembled. One millilitres of $\mathrm{HNO}_{3}(1 \mathrm{M})$ was added in a closed microvial to elute metal from resin gel for $24 \mathrm{~h}$.

After retrieval of the DGT device, the soil paste was stirred and then centrifuged at $3000 \mathrm{rpm}$ for $30 \mathrm{~min}$ to obtain the soil solution. The supernatant was syringe-filtered using $13-\mathrm{mm}-$ diameter, $0.45-\mu \mathrm{m}$-pore diameter disposable polysulfone filter assemblies (Whatman, Kent, UK) and was then used for DOC analysis.

\subsection{Soil sample chemical analysis}

Eluted metals from the resin gel of DGT by $\mathrm{HNO}_{3}$ were determined by inductively coupled plasma-mass spectrometry (ICP-MS; Varian Ultramass, Melbourne, VIC, Australia) within various calibration ranges after appropriate dilution using $\mathrm{Rh}$ as internal standard.

Soil solution DOC determination followed the twocomponent model of UV absorbance according to Tipping et al. (2009) and was analysed by UV/Vis absorption (Genesys 10s, Thermo Scientific) at wavelengths of 254 and $340 \mathrm{~nm}$. The parameters used in the model for calculation of DOC were gained from Cater et al. (2012). Although this method cannot give the exact DOC concentration in the soil solution as obtained by traditional methods, the change in DOC following change in soil water regime can be determined. For the DOC analysis, all soil solutions were diluted by one factor with deionized water, and deionized water was also used as the blank.

\subsection{Statistical analysis}

Statistical analysis was performed using the SPSS version 16.0 for Windows software package (SPSS Inc., Chicago, IL). Mean values were compared after analysis of variance using Duncan's multiple range test at the $5 \%$ level in each water regime. Data are presented as mean \pm standard error (SE) $(n=3)$. The correlations between available metal estimated by DGT and DOC in the soil solution were examined using Pearson's test at the 5 and $1 \%$ levels of significance.

\section{Results}

\subsection{DOC in soil solutions}

The two-component model of UV absorbance (at 254 and $340 \mathrm{~nm}$ ) was used to discriminate DOC changes in the soil solution and the data are shown in Fig. 1. In regime 1 (flooded to moderately wet drying), DOC in HLD-NR decreased with soil drying in the first cycle, and was high at $100 \%$ WHC (F2$100)$ in the second cycles, but HLD-R showed no significant difference in DOC concentration in regime 1. In regime 2 (wet to severe drying), DOC was lower at the intermediate water content (M1-50 and M2-50) for both cycles of both soils with the exception of the second cycle of HLD-R.

In the calcareous soil (ZJW-NR/R), similar DOC changes were found in regimes 1 and 2. In regime 1, DOC was high at $100 \% \mathrm{WHC}$ in each cycle and decreased with soil drying in regime 2. In addition, the soil in the first cycle had higher DOC concentrations than that in the second cycle in both regimes. In regime 3 , all soils showed the same changes in DOC. The highest DOC was found in the control followed by $\mathrm{F} 1$ and M1 which were higher than F2 and M2, respectively. In addition, DOC concentrations in soils with phytoextraction were several times higher than in soils without phytoextraction. Within each water regime, across the range of soil moisture contents investigated, the changes in DOC observed were statistically significant (Fig. 1).

\subsection{Metal availability measured by DGT}

The changes in available metal evaluated by DGT $\left(C_{\mathrm{DGT}}\right)$ in soils subjected to different water regimes are shown in Figs. 2 and 3. In acid soils (HLD-NR/R), $C_{\mathrm{DGT}}$ of aluminium (Al), cadmium $(\mathrm{Cd})$, nickel $(\mathrm{Ni})$ and zinc $(\mathrm{Zn})$ showed a slight or significant increase with the drying process over both cycles in regime 1, with the exception of the first cycles of HLD-R which showed no significant change (Fig. 2). In regime 2, none of the metals showed any significant differences in concentration between treatments with the exception of the lower $\mathrm{Zn}$ and $\mathrm{Cd}$ in HLD-R at $50 \%$ WHC. In regime 3, Al in acid soils (HLD-NR and HLD-R) and $\mathrm{Ni}, \mathrm{Cd}$ and $\mathrm{Zn}$ in 

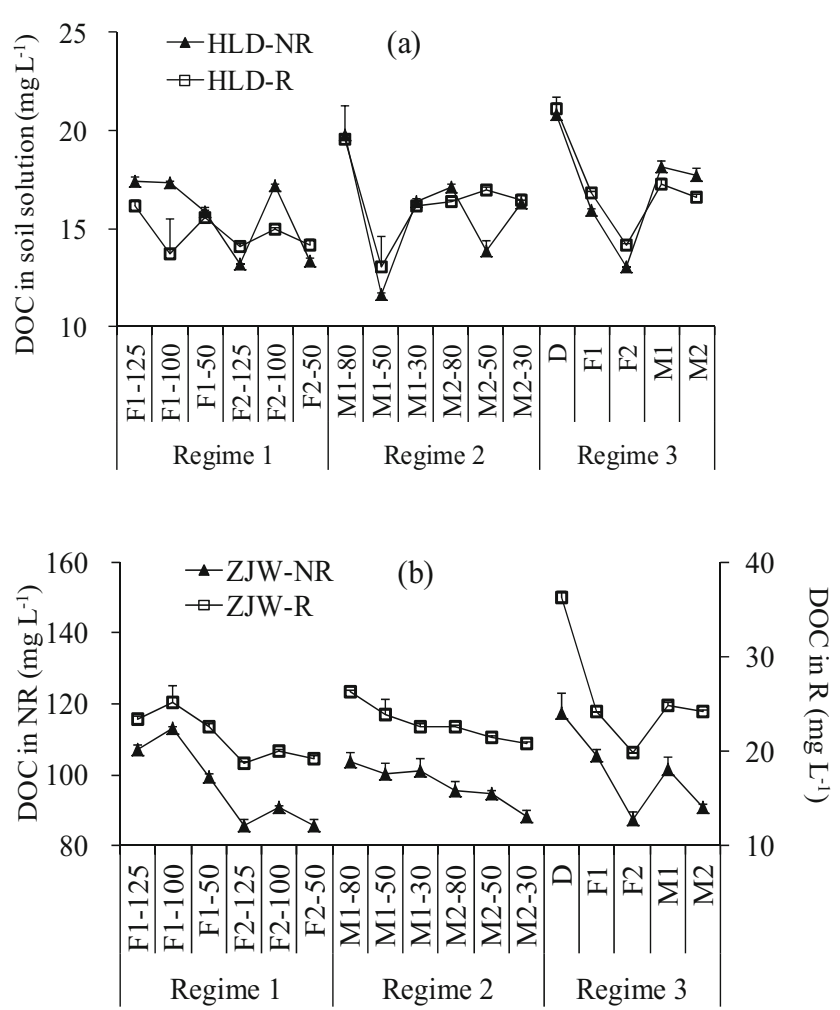

Fig. 1 Dissolved organic carbon $(D O C)$ in soil solution in HLD (a) and ZJW (b) soils with $(R)$ and without $(N R)$ phytoextraction under different experimental regimes and conditions. Note: regimes 1 and 2 denote soils subjected to flooded-drying $(F)$ or moderate wetting-drying $(M)$ cycles respectively; 1 and 2 refer to the wetting-drying frequency; $125,100,80$, 50 and 30 denote soil water content; regime 3 denotes soils dried from flooded ( $F 1$ and $F 2$ ), moderate wet ( $M 1$ and $M 2$ ) or soil with long duration drying (D). The error bars are standard errors, $n=3$

phytoremediated acid soil (HLD-R) followed the order $\mathrm{M} 2>\mathrm{M} 1>\mathrm{D}, \mathrm{F} 1$, and $\mathrm{F} 2$, but copper $(\mathrm{Cu})$ of $C_{\mathrm{DGT}}$ in HLD$\mathrm{NR}$ and HLD-R and $\mathrm{Ni}, \mathrm{Cd}$ and $\mathrm{Zn}$ of $C_{\mathrm{DGT}}$ in nonphytoremediated acid soil (HLD-NR) followed the order $\mathrm{M} 2, \mathrm{M} 1, \mathrm{D}>\mathrm{F} 1>\mathrm{F} 2$. Moreover, the $\mathrm{Ni}, \mathrm{Zn}$ and $\mathrm{Cd}$ of $C_{\mathrm{DGT}}$ in regime 2 of HLD-NR were significantly higher than in regime $1(p<0.05)$.

In contrast to the acid soils, $C_{\text {DGT }}$ of metals in the calcareous soils generally decreased with the drying process for both cycles of regimes 1 and 2 with some exceptions. Nickel showed no decreasing trend in the first cycle of regimes 1 and 2, and $\mathrm{Cd}$ and $\mathrm{Zn}$ were lower at F1-125. In regime 3, $C_{\text {DGT }}$ values of $\mathrm{Ni}$ and $\mathrm{Cu}$ in treatment $\mathrm{D}$ were significantly higher than in the other treatments. Zinc and Cd in treatment D were similar to $\mathrm{M} 1$ and $\mathrm{M} 2$ which were higher than $\mathrm{F} 1$ and $\mathrm{F} 2$. In addition, $C_{\mathrm{DGT}}$ of all the metals determined showed F1 $>\mathrm{F} 2$ for ZJW-NR and ZJW-R and M1 > M2 for ZJW-R.

\subsection{Correlations between DOC and available metals}

The coefficients of determination, $r^{2}$, obtained from correlations between DOC and available metals are presented in
Tables 2 and 3. In the acid soils, $\mathrm{Al}, \mathrm{Cd}, \mathrm{Ni}$ and $\mathrm{Zn}$ had strong positive linear relationships between each other $\left(r^{2}=0.71-\right.$ $0.91, p<0.01, n=17$ ) in all HLD-R samples but with lower correlation coefficients between $\mathrm{Al}$ and the other metals in HLD-NR than the HLD-R. Copper had a good linear correlation with DOC for HLD-R $\left(r^{2}=0.40, p<0.01, n=17\right)$ but not for HLD-NR (Table 3). In regime $3, \mathrm{Cu}$ had strong linear correlations with DOC in both HLD-R and HLD-NR $\left(r^{2}=\right.$ 0.93 and 95 , both $p<0.01, n=5$ ). In the alkaline soils, $\mathrm{Cu}$ had good correlations with DOC in ZJW-NR/R $\left(r^{2}=0.45\right.$ and $0.75, p<0.01, n=17$ ) in all water regimes, as did $\mathrm{Ni}$ in ZJW-R $\left(r^{2}=0.35, p<0.05, n=17\right)$ (Table 4). Much higher correlations between $\mathrm{Cu}$ and $\mathrm{Ni}$ and $\mathrm{DOC}$ were found in regime 3 of ZJW-NR/R $\left(r^{2}=0.95\right.$ and 0.98 for $\mathrm{Cu}$ and 0.64 and 0.95 for $\mathrm{Ni}$, all $p<0.01, n=5$ ).

\section{Discussion}

\subsection{Changes in soil solution DOC}

The two-component model of UV absorbance was used to estimate the quantity of DOC in the soil solution under the different water treatments. In the present study, the DOC in the soil solution varied with soil type and with soil moisture content (Fig. 1). In regime 1, the highest concentrations of DOC appeared at a water content of $100 \%$ WHC in each cycle with the exception of the first cycle of the HLD soils (Fig. 1a, b). The DOC changes in soil wetting-drying processes were very complex, and both chemical and biochemical mechanisms may be involved. Soil Eh will change greatly during the soil wetting-drying processes (Cornu et al. 2007; Yamaguchi et al. 2011; Shaheen et al. 2014a, b). Studies find that DOC concentration usually decreases with increasing soil Eh (Grybos et al. 2007; Yu et al. 2007; Frohne et al. 2014). Possible mechanism during the soil wetting-drying cycles may be related to the following two aspects. Under reducing conditions, $\mathrm{Fe} / \mathrm{Al} /$ Mn- (hydr) oxides may dissolve and result in the release of the combined organic matter (Grybos et al. 2007). Inversely, the forms of $\mathrm{Fe} / \mathrm{Al} / \mathrm{Mn}$ - (hydr) oxides may complex with the DOC from the soil solution when the soil is in oxidizing conditions. In addition, changes in soil Eh conditions may also occur with a possible shift in microbial community composition (Drenovsky et al. 2004), and the microbial activities can also decrease soil solution DOC by releasing soluble organic metabolites or enhance DOC by microbial carbon consumption (Chow et al. 2006; Yu et al. 2007). The hydrolysis of dead microorganisms and soil organic matter by microbial consumption will increase the DOC (125 to $100 \%$ WHC), while the increasing numbers of new microorganisms will consume DOC and may result in a decrease in DOC when the soil is dried from 100 to $50 \%$ WHC. Furthermore, desorption of soil organic matter to solution may be influenced by changing $\mathrm{pH}$ 
Fig. 2 Metal of $C_{\mathrm{DGT}}$ of HLD with $(R)$ and without $(N R)$ phytoextraction under different water regime treatments. The error bars are standard errors, $n=3$
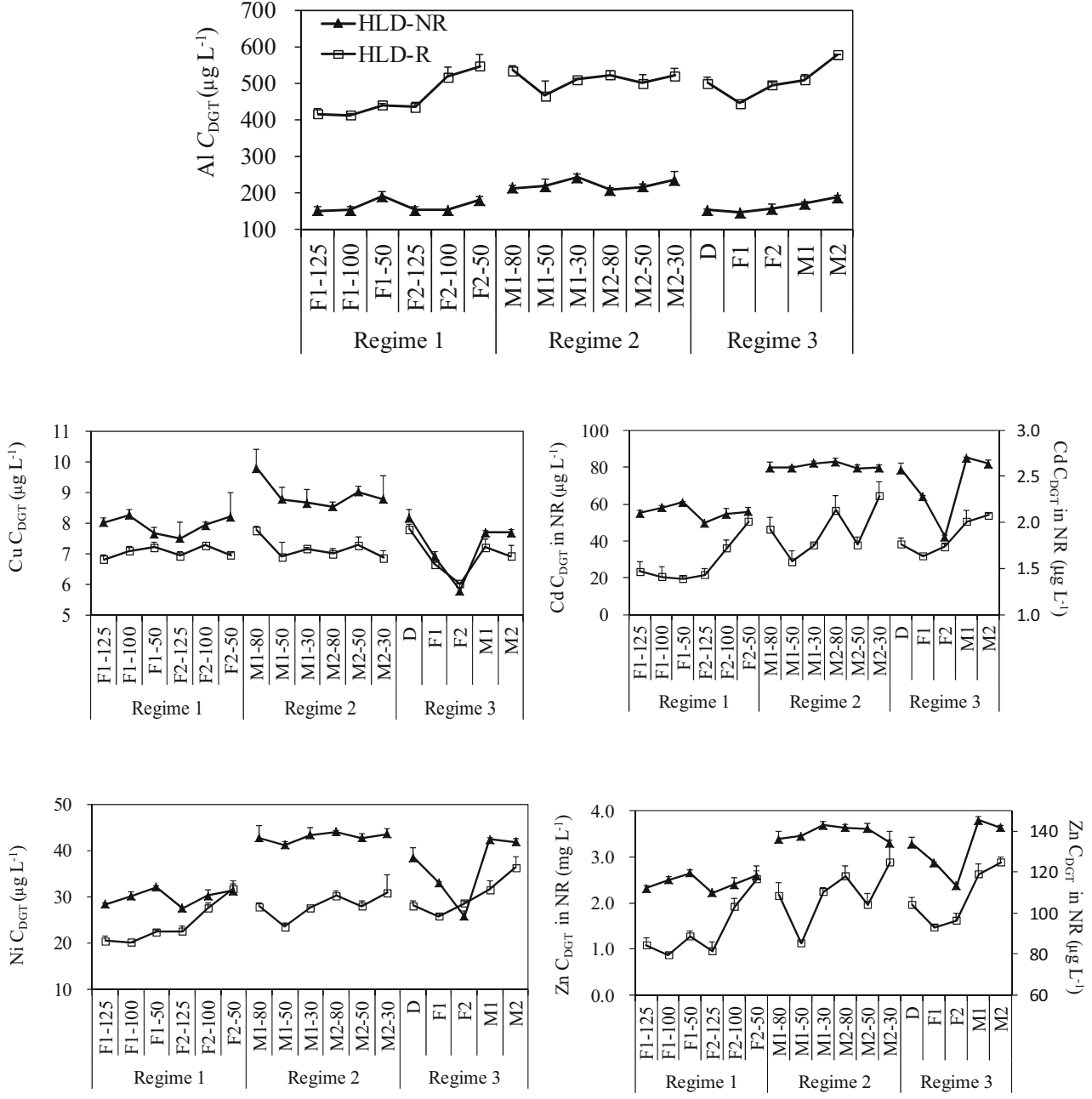

in the wetting-drying processes. Increasing soil $\mathrm{pH}$ can increase the negative charge of soil mineral surfaces, and this can promote desorption of the positively charged DOC. Grybos et al. (2009) found that most of the total released DOC is associated with increasing $\mathrm{pH}$ under reducing conditions. These contrasting effects on DOC will occur simultaneously during the drying process, and the net effect will depend on the microbes and the labile organic matter (including dead microbes) present.

In regime 2, the soils were dried from 100 to $30 \% \mathrm{WHC}$, and the HLD soils had the lowest DOC at $50 \%$ WHC in each cycle with the exception of the second cycle of HLD-R (Fig. 1). When soils are subjected to moderate drying, microorganisms will accumulate organic solutes (e.g. amino acids and polyols) from the soil solution and thus decrease the osmotic potential as the water potential decreases (Borken and Matzner 2009). This may result in a decrease in DOC when the soil is dried from 80 to $50 \%$ WHC (Fig. 1a). With further drying, microorganisms will die and hydrolyse (Borken and Matzner 2009), and this might explain the increase in DOC when soil is dried from 50 to $30 \%$ WHC (Fig. 1a). However, this explanation cannot apply to ZJW soils in which the DOC showed a gradual decreasing trend during the water treatments (Fig. 1b). In this study, the soils used were rewetted from the dried condition, and this may have promoted a high carbon mineralization rate and high DOC concentration, a so-called wetting pulse (Jarvis et al. 2007). The wetting pulse will decrease with increasing frequency of drying and wetting (Borken and Matzner 2009). This declining effect of the wetting pulse could control the DOC changes in regime 2 of ZJW and is also supported by the significantly lower DOC in the second cycle compared with the first cycle of regime 1 (Fig. 1b). Guo et al. (2012) also found significant increases in DOC with increasing frequency of wetting-drying cycles.

In regime 3, the soil dried over the long term (D) had the largest DOC (Fig. 1). The soils that were newly dried after wetting-drying cycles (F1, F2, M1 and M2) had lower DOC contents, and the DOC further decreased with increasing duration of drying-wetting cycle (Fig. 1). This effect may result from a decrease in labile organic matter or a shift in the microbial community because of adaptation to the stress of the 

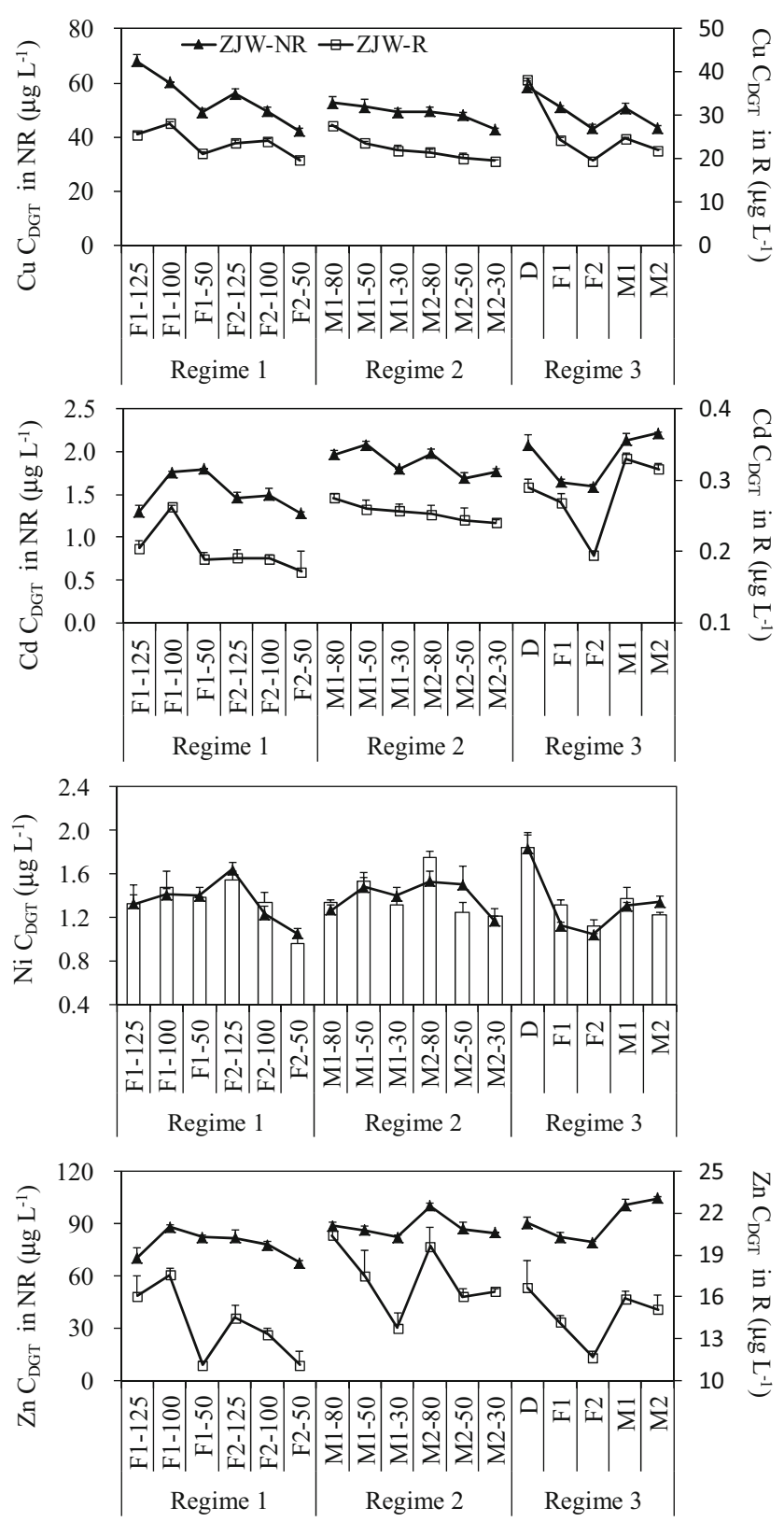

Fig. 3 Metal of $C_{\text {DGT }}$ of ZJW with $(R)$ and without $(N R)$ phytoextraction under different water regime treatments. The error bars are standard errors, $n=3$

drying-wetting process as discussed in the review of Borken and Matzner (2009).

\subsection{Changes in metal availability during soil drying}

In the acid soil, the increases in $\mathrm{Cd}, \mathrm{Ni}$ and $\mathrm{Zn}$ availability were found when HLD-NR and HLD-R were dried from flooded to $50 \%$ WHC (water regime 1) (Fig. 2). This is consistent with previous reports that air-drying increases the amount of $\mathrm{Cd}$ desorbed from acid soils $(\mathrm{pH}<6.0)$ (Tang et al. 2011) and that flooding decreases soil $(\mathrm{pH}, 5.5) \mathrm{NH}_{4} \mathrm{OAc}-$ extractable $\mathrm{Cd}, \mathrm{Ni}$ and $\mathrm{Zn}$ by 97,47 and $87 \%$, respectively
Table 3 Coefficients of determination obtained from correlation of $C_{\mathrm{DGT}}$ for various metals and dissolved organic carbon (DOC) in the soil solution for soil HLD with (R) and without (NR) phytoremediation

\begin{tabular}{lllllll}
\hline $\mathrm{R}$ & $\mathrm{Al}$ & $\mathrm{Cu}$ & $\mathrm{Cd}$ & $\mathrm{Ni}$ & $\mathrm{Zn}$ & $\mathrm{DOC}$ \\
\hline $\mathrm{Al}$ & 1 & 0.02 & $0.71^{* *}$ & $0.86^{* *}$ & $0.80^{* *}$ & 0.12 \\
$\mathrm{Cu}$ & $0.37^{* *}$ & 1 & 0 & 0 & 0.01 & $0.40^{* *}$ \\
$\mathrm{Cd}$ & $0.47^{* *}$ & $0.37^{* *}$ & 1 & $0.79^{* *}$ & $0.91^{* *}$ & 0.13 \\
$\mathrm{Ni}$ & $0.60^{* *}$ & $0.37^{* *}$ & $0.96^{* *}$ & 1 & $0.87^{* *}$ & 0.12 \\
$\mathrm{Zn}$ & $0.48^{* *}$ & $0.22^{*}$ & $0.94^{* *}$ & $0.95^{* *}$ & 1 & 0.17 \\
$\mathrm{DOC}$ & -0.03 & 0.05 & 0.10 & 0.05 & 0.04 & 1 \\
\hline
\end{tabular}

Pearson correlation

*Significant at the 0.05 level (two-tailed); $n=17$

**Significant at the 0.01 level (two-tailed)

(Kashem and Singh 2004) and soil DTPA-extractable Cd (Zhu et al. 2012). Flooding can lower the soil redox potential (Eh) and increase the hydrous oxides of $\mathrm{Fe}, \mathrm{Mn}$ and $\mathrm{Al}$, and this can increase metal adsorption (Kashem and Singh 2004). In addition, flooding can increase the $\mathrm{pH}$ of acid soils (Zhu et al. 2012) and thus increase the amount of soil surface negative charges and decrease the competition between $\mathrm{H}^{+}$ions and metals for surface adsorption sites and thus decrease metal availability (Naidu et al. 1997). These changes may be responsible for the increase in available metal with soil drying from flooded to $50 \%$ WHC. In the process of soil drying from 100 to $30 \% \mathrm{WHC}$ (regime 2), changes in metal availability were not significant, although in HLD-R, slightly lower availabilities of $\mathrm{Cd}, \mathrm{Ni}$ and $\mathrm{Zn}$ were found at $50 \% \mathrm{WHC}$ than at other moisture contents in each cycle (Fig. 2).

In contrast to the acid soils, a decreasing trend in the available fractions of all metals studied was found with soil drying in water regimes 1 and 2 in the calcareous soils (Fig. 3). Wang et al. (2012) also found that compared to flooded calcareous soils, dried soils had less acid soluble and reducible metal fractions. There are several possible explanations that can

Table 4 Coefficients of determination obtained from correlation of $C_{\mathrm{DGT}}$ for various metals and dissolved organic carbon (DOC) in soil solution for soil ZJW with (R) and without (NR) phytoremediation

\begin{tabular}{llllll}
\hline $\mathrm{R}$ & $\mathrm{Cu}$ & $\mathrm{Cd}$ & $\mathrm{Ni}$ & $\mathrm{Zn}$ & $\mathrm{DOC}$ \\
$\mathrm{Nu}$ & 1 & 0.16 & $0.44^{* *}$ & 0.16 & $0.75^{* *}$ \\
$\mathrm{Cd}$ & 0.02 & 1 & 0.07 & $0.32^{*}$ & $0.43^{* *}$ \\
$\mathrm{Ni}$ & $0.23^{*}$ & 0.16 & 1 & $0.29^{*}$ & $0.35^{*}$ \\
$\mathrm{Zn}$ & 0.02 & $0.79^{* *}$ & 0.14 & 1 & 0.21 \\
$\mathrm{DOC}$ & $0.45^{* *}$ & 0.14 & 0.19 & 0.05 & 1 \\
\hline
\end{tabular}

Pearson correlation

*Significant at the 0.05 level (two-tailed); $n=17$

$* *$ Significant at the 0.01 level (two-tailed) 
account for this. Firstly, the high concentration of DOC may be correlated with the increase in soluble metals. Decomposition of soil organic matter can release the combined metal (Grybos et al. 2007), and the increased DOC can also induce metal mobilization by formation of metalDOC complexes (Du Laing et al. 2009a). This applies especially to $\mathrm{Cu}$ and $\mathrm{Ni}$ which have high affinity with DOC (Amery et al. 2008). In this study, the positive linear relationships between DOC and $C_{\mathrm{DGT}}$ of $\mathrm{Cu}$ and $\mathrm{Ni}$ in calcareous soil of ZJW were also found (Table 4). Secondly, in regime 1, drying calcareous soil from flooded conditions can lead to an increase in soil pH (Fageria et al. 2011), and this can decrease metal availability by increasing metal sorption on soil surfaces and formation of precipitates. However, the availabilities of $\mathrm{Cd}$, Ni and $\mathrm{Zn}$ at $125 \% \mathrm{WHC}$ were unexpectedly low or significantly lower than at $100 \% \mathrm{WHC}$ in the first cycle, but this effect was absent from the second cycle (Fig. 3). This might be related to larger amounts of available organic matter in the soil during the first wetting (Borken and Matzner 2009), resulting in a much lower Eh with microbial anaerobic respiration and decomposition of organic matter after the flooding of the soil (Liu et al. 2012). This could result from increased metal retention with $\mathrm{Fe} / \mathrm{Mn}$ oxides or the formation of metal precipitates with $\mathrm{S}^{2-}$ (Du Laing et al. 2009a; Borch et al. 2010).

\subsection{Effects of previous soil water processes on soil metal availability}

Previous soil wetting-drying cycles can change the Fe/Al/Mn(hydr) oxide forms and DOC concentrations, and result in variations in metal availability (Lundquist et al. 1999; Tack et al. 2006). In this study, the effects of previous wettingdrying processes on metal availability based on DGT depended on metal species and soil type. Copper of $C_{\mathrm{DGT}}$ in all four soils and $\mathrm{Ni}$ in calcareous soils (ZJW-R, ZJW-NR) were the highest in $\mathrm{D}$ (the soils dried over a 6-month period), followed by the samples with one wetting-drying cycle (F1 and M1), which were higher than F2 and M2, respectively (Figs. 2 and 3). This variation is consistent with the DOC changes which decreased as the wetting-drying cycles increased in regime 3 (Fig. 1). Correlation analysis shows that available $\mathrm{Ni}$ and $\mathrm{Cu}$ had good linear relationships with DOC in ZJW in regime $3\left(r^{2}, 0.64-0.98, n=5\right)$. This indicates that DOC may be the main factor affecting $\mathrm{Cu}$ or $\mathrm{Ni}$ availability and is confirmed by the high affinity for DOC of these two metals. In contrast to available $\mathrm{Cu}$, a wetting-drying cycle increased the availability of $\mathrm{Ni}, \mathrm{Cd}$ and $\mathrm{Zn}$ in phytoremediated acid soil (HLD-R) in the sequence M2 $>\mathrm{M} 1>\mathrm{D}, \mathrm{F} 1$ and $\mathrm{F} 2$ (Fig. 2). Amorphous $\mathrm{Fe} / \mathrm{Mn} / \mathrm{Al}$ oxides play an important role in the retention of metals (Axe and Trivedi 2002; Kashem and Singh 2004; Shaheen 2009). Flooding and then drying soils can significantly change the amorphous $\mathrm{Fe}$ and $\mathrm{Al}$ oxides (Xia et al. 2011). Correlation analysis shows that available $\mathrm{Ni}, \mathrm{Cd}$ and $\mathrm{Zn}$ had good linear relationships with available $\mathrm{Al}$ in HLD-R in regime $3\left(r^{2}, 0.76-0.93, n=5\right)$. This may suggest that the shift in $\mathrm{Al}$ speciation (possibly also for $\mathrm{Mn}$ and $\mathrm{Fe}$ ) plays a role controlling $\mathrm{Ni}, \mathrm{Cd}$ and $\mathrm{Zn}$ availability under these conditions. However, different changes in these three metals were found in regime 3 of HLD-NR (Fig. 2). This may be explained by the effects of phytoextraction, and the phytoextracted soil with HLD-R had more than twice the available $\mathrm{Al}$ of the non-phytoextracted soil (HLD-NR) (Fig. 2). These increases in available $\mathrm{Al}$ (possibly also for $\mathrm{Fe}$ and $\mathrm{Mn}$, but not determined in this study) might easily shift between $\mathrm{Al}$ fractions during the wetting-drying and thus greatly affect metal availability. For HLD-NR, the poor linear correlations between available $\mathrm{Cd}, \mathrm{Ni}$ and $\mathrm{Zn}$ and available $\mathrm{Al}$ (and also DOC) indicate that the main factor affecting the availability of these three metals was neither $\mathrm{Al}$ oxides nor DOC in regime 3 but may represent the combined effects of oxides and DOC.

In view of the remarkable effects of soil water regimes on metal availability in this study, soil metal availability can be manipulated to alleviate soil metal environmental risk or to enhance soil available metal for the purpose of phytoremediation. However, it should also be kept in mind that the results of this study carried out under laboratory conditions might be different from field conditions. According to Du Laing et al. (2009b) and Rupp et al. (2010), the effects of soil water changes on metal availability were less pronounced in field conditions than in controlled greenhouse conditions. This difference might be attributable to three factors: firstly, the more distinct variation in the redox potential in controlled conditions; secondly, the sieved and air-dried soils used in the laboratory might result in different changes in available metal fractions compared to natural undisturbed soils; and thirdly, differences in soil sampling and sample processing may lead to different effects on soil biological properties which in turn influence metal availability (Du Laing et al. 2009b). Although less pronounced effects in field conditions, the same factors control metal mobility induced by soil water variations in greenhouse and field conditions (Du Laing et al. 2009b), and the changing trend of metal availability is also similar in laboratory and field conditions (Rennert et al. 2010; Rupp et al. 2010).

\section{Conclusions}

Two types of soil drying conditions and different wettingdrying cycles before drying were found to affect metal availability in the four contaminated soil treatments. In acid soil, available $\mathrm{Cd}, \mathrm{Ni}$ and $\mathrm{Zn}$ (but not $\mathrm{Cu}$ ) increased with soil drying from flooded to $50 \% \mathrm{WHC}$ conditions. The effect of drying soil from 100 to $30 \%$ WHC on metal availability 
was weak. In contrast, in the calcareous soils, the availabilities of all the metals examined showed decreasing trends when the soil was dried from saturation (flooded) to $50 \% \mathrm{WHC}$ or from 100 to $30 \%$ WHC. These results indicate that soil drying processes can change the availability of metals in ways that differ with different metals and different soil types. Soils subjected to different moisture treatments before drying also displayed significant differences in metal availability. Soil moisture content before drying was important when dried soils were used for evaluation of metal availability.

Acknowledgments This research was supported by the National Natural Science Foundation of China (41325003, 41271326) and the National High Technology Research and Development Program ('863' Program) of China (2012AA06A204).

\section{References}

Amery F, Degryse F, Cheyns K, De Troyer I, Mertens J, Merckx R, Smolders E (2008) The UV-absorbance of dissolved organic matter predicts the fivefold variation in its affinity for mobilizing $\mathrm{Cu}$ in an agricultural soil horizon. Eur J Soil Sci 59:1087-1095

Arunakumara KKIU, Walpola BC, Yoon MH (2012) Current status of heavy metal contamination in Asia's rice lands. Rev Environ Sci Biotechnol 12:355-377

Axe L, Trivedi P (2002) Intraparticle surface diffusion of metal contaminants and their attenuation in microporous amorphous $\mathrm{Al}, \mathrm{Fe}$, and Mn oxides. J Colloid Interface Sci 247:259-265

Blaylock MJ, Salt DE, Dushenkov S, Zakharova O, Gussman C, Kapulnik Y, Ensley BD, Raskin I (1997) Enhanced accumulation of $\mathrm{Pb}$ in Indian mustard by soil-applied chelating agents. Environ Sci Technol 31:860-865

Borch T, Kretzschmar R, Kappler A, Van Cappellen P, Ginder-Vogel M, Voegelin A, Campbell K (2010) Biogeochemical redox processes and their impact on contaminant dynamics. Environ Sci Technol 44: $15-23$

Borken W, Matzner E (2009) Reappraisal of drying and wetting effects on $\mathrm{C}$ and $\mathrm{N}$ mineralization and fluxes in soils. Glob Chang Biol 15: 808-824

Cater HT, Tipping E, Koprivnjak JF, Miller MP, Cookson B, HamiltonTaylor J (2012) Freshwater DOM quantity and quality from a twocomponent model of UV absorbance. Water Res 46:4532-4542

Chow AT, Tanji KK, Gao SD, Dahlgren RA (2006) Temperature, water content and wet-dry cycle effects on DOC production and carbon mineralization in agricultural peat soils. Soil Biol Biochem 38:477488

Cornu JY, Denaix L, Schneider A, Pellerin S (2007) Temporal evolution of redox processes and free $\mathrm{Cd}$ dynamics in a metal-contaminated soil after rewetting. Chemosphere 70:306-314

Davison W, Zhang H (1994) In situ speciation measurements of trace components in natural waters using thin-film gels. Nature 367 : $546-548$

Davison W, Hooda PS, Zhang H, Edwards AC (2000) DGT measured fluxes as surrogates for uptake of metals by plants. Adv Environ Res 3:550-555

de Vries W, McLaughlin MJ, Groenenberg JE (2011) Transfer functions for solid-solution partitioning of cadmium for Australian soils. Environ Pollut 159:3583-3594
Drenovsky RE, Vo D, Graham KJ, Scow KM (2004) Soil water content and organic carbon availability are major determinants of soil microbial community composition. Microb Ecol 48:424 430

Du Laing G, Meers E, Dewispelaere M, Vandecasteele B, Rinklebe J, Tack FMG, Verloo MG (2009a) Heavy metal mobility in intertidal sediments of the Scheldt estuary: field monitoring. Sci Total Environ 407:2919-2930

Du Laing G, Rinklebe J, Vandecasteele B, Meers E, Tack FM (2009b) Trace metal behaviour in estuarine and riverine floodplain soils and sediments: a review. Sci Total Environ 407:3972-3985

Fageria NK, Carvalho GD, Santos AB, Ferreira EPB, Knupp AM (2011) Chemistry of lowland rice soils and nutrient availability. Commun Soil Sci Plan 42:1913-1933

Fest EPMJ, Temminghoff EJM, Comans RAJ, van Riemsdijk WH (2008) Partitioning of organic matter and heavy metals in a sandy soil: effects of extracting solution, solid to liquid ratio and $\mathrm{pH}$. Geoderma 146:66-74

Frohne T, Rinklebe J, Diaz-Bone RA (2014) Contamination of floodplain soils along the Wupper River, Germany, with $\mathrm{As}, \mathrm{Co}, \mathrm{Cu}, \mathrm{Ni}, \mathrm{Sb}$, and $\mathrm{Zn}$ and the impact of pre-definite redox variations on the mobility of these elements. Soil Sediment Contam 23:779-799

Groenenberg JE, Römkens PFAM, Comans RNJ, Luster J, Pampura T, Shotbolt L, Tipping E, de Vires W (2010) Transfer functions for solid-solution partitioning of cadmium, copper, nickel, lead and zinc in soils: derivation of relationships for free metal ion activities and validation with independent data. Eur J Soil Sci 61:58-73

Grybos M, Davranche M, Gruau G, Petitjean P (2007) Is trace metal release in wetland soils controlled by organic matter mobility or Fe-oxyhydroxides reduction? J Colloid Interface Sci 314:490-501

Grybos M, Davranche M, Gruau G, Petitjean P, Pedrot M (2009) Increasing $\mathrm{pH}$ drives organic matter solubilization from wetland soils under reducing conditions. Geoderma 154:13-19

Guo XB, Drury CF, Yang XM, Reynolds WD, Zhang RD (2012) Impacts of wet-dry cycles and a range of constant water contents on carbon mineralization in soils under three cropping treatments. Soil Sci Soc Am J 76:485-493

Hu PJ, Li Z, Yuan C, Ouyang YN, Zhou LQ, Huang JX, Huang YJ, Luo YM, Christie P, Wu LH (2013) Effect of water management on cadmium and arsenic accumulation by rice (Oryza sativa L.) with different metal accumulation capacities. J Soils Sediments 13:916924

Huang ZY, Chen T, Yu JA, Zeng XC, Huang YF (2011) Labile Cd and Pb in vegetable-growing soils estimated with isotope dilution and chemical extractants. Geoderma 160:400-407

Jarvis P, Rey A, Petsikos C, Wingate L, Rayment M, Pereira J, Banza J, David J, Miglietta F, Borghetti M (2007) Drying and wetting of Mediterranean soils stimulates decomposition and carbon dioxide emission: the "Birch effect". Tree Physiol 27:929-940

Jiang JP, Wu LH, Li N, Luo YM, Liu L, Zhao QG, Zhang L, Christie P (2010) Effects of multiple heavy metal contamination and repeated phytoextraction by Sedum plumbizincicola on soil microbial properties. Eur J Soil Biol 46:18-26

Kashem MA, Singh BR (2004) Transformations in solid phase species of metals as affected by flooding and organic matter. Commun Soil Sci Plan 35:1435-1456

Li Z, Wu LH, Hu PJ, Luo YM, Zhang H, Christie P (2014a) Repeated phytoextraction of four metal-contaminated soils using the cadmium/zinc hyperaccumulator Sedum plumbizincicola. Environ Pollut 189:176-183

Li ZY, Ma ZW, van der Kuijp TJ, Yuan ZW, Huang L (2014b) A review of soil heavy metal pollution from mines in China: pollution and health risk assessment. Sci Total Environ 468-469:843-853

Liu JB, Hou HJ, Sheng R, Chen Z, Zhu YJ, Qin HL, Wei WX (2012) Denitrifying communities differentially respond to flooding drying cycles in paddy soils. Appl Soil Ecol 62:155-162 
Lundquist EJ, Jackson LE, Scow KM (1999) Wet-dry cycles affect dissolved organic carbon in two California agricultural soils. Soil Biol Biochem 31:1031-1038

Menzies NW, Donn MJ, Kopittke PM (2007) Evaluation of extractants for estimation of the phytoavailable trace metals in soils. Environ Pollut 145:121-130

Naidu R, Kookana RS, Sumner ME, Harter RD, Tiller KG (1997) Cadmium sorption and transport in variable charge soils: a review. J Environ Qual 26:602-617

Rennert T, Meissner S, Rinklebe J, Totsche KU (2010) Dissolved inorganic contaminants in a floodplain soil: comparison of in situ soil solutions and laboratory methods. Water Air Soil Pollut 209:489500

Rupp H, Rinklebe J, Bolze S, Meissner R (2010) A scale-dependent approach to study pollution control processes in wetland soils using three different techniques. Ecol Eng 36:1439-1447

Shaheen SM (2009) Sorption and lability of cadmium and lead in different soils from Egypt and Greece. Geoderma 153:61-68

Shaheen SM, Rinklebe J, Rupp H, Meissner R (2014a) Temporal dynamics of pore water concentrations of $\mathrm{Cd}, \mathrm{Co}, \mathrm{Cu}, \mathrm{Ni}$, and $\mathrm{Zn}$ and their controlling factors in a contaminated floodplain soil assessed by undisturbed groundwater lysimeters. Environ Pollut 191:223-231

Shaheen SM, Rinklebe J, Rupp H, Meissner R (2014b) Lysimeter trials to assess the impact of different flood-dry-cycles on the dynamics of pore water concentrations of $\mathrm{As}, \mathrm{Cr}, \mathrm{Mo}$ and $\mathrm{V}$ in a contaminated floodplain soil. Geoderma 228:5-13

Tack FMG, Van Ranst E, Lievens C, Vandenberghe RE (2006) Soil solution $\mathrm{Cd}, \mathrm{Cu}$ and $\mathrm{Zn}$ concentrations as affected by short-time drying or wetting: the role of hydrous oxides of Fe and Mn. Geoderma 137: 83-89

Tandy S, Mundus S, Yngvesson J, de Bang TC, Lombi E, Schjoerring JK, Husted S (2011) The use of DGT for prediction of plant available copper, zinc and phosphorus in agricultural soils. Plant Soil 346: $167-180$
Tang XY, Katou H, Suzuki K, Ohtani T (2011) Air-drying and liming effects on exchangeable cadmium mobilization in contaminated soils: a repeated batch extraction study. Geoderma 161:18-29

Tipping E, Corbishley HT, Koprivnjak JF, Lapworth DJ, Miller MP, Vincent CD, Hamilton-Taylor J (2009) Quantification of natural DOM from UV absorption at two wavelengths. Environ Chem 6: 472-476

Wang B, Huang B, Qi YB, Hu WY, Sun WX (2012) Effect of air drying on speciation of heavy metal in flooded rice paddies. Chin Chem Lett 23:1287-1290

Williams PN, Zhang H, Davison W, Zhao SZ, Lu Y, Dong F, Zhang L, Pan Q (2012) Evaluation of in situ DGT measurements for predicting the concentration of $\mathrm{Cd}$ in Chinese field-cultivated rice: impact of soil Cd:Zn ratios. Environ Sci Technol 46:8009-8016

Xia JG, Zhong YM, Cao XX (2011) Relation between phosphorous release and soil character with alternative dry-wet conditions. J Soil Water Conserv 25:237-242 (in Chinese)

Xu JZ, Wei Q, Yu YM, Peng SZ, Yang SH (2013) Influence of water management on the mobility and fate of copper in rice field soil. $\mathrm{J}$ Soils Sediments 13:1180-1188

Yamaguchi N, Nakamura T, Dong D, Takahashi Y, Amachi S, Makino T (2011) Arsenic release from flooded paddy soils is influenced by speciation, Eh, pH, and iron dissolution. Chemosphere 83:925-932

Yang JC, Huang DF, Duan H, Tan GL, Zhang JH (2009) Alternate wetting and moderate soil drying increases grain yield and reduces cadmium accumulation in rice grains. J Sci Food Agric 89:17281736

Yu KW, Bohme F, Rinklebe J, Neue HU, DeLaune RD (2007) Major biogeochemical processes in soils - a microcosm incubation from reducing to oxidizing conditions. Soil Sci Soc Am J 71:1406-1417

Zhang H, Zhang SF, Yang JC, Zhang JH, Wang ZQ (2008) Postanthesis moderate wetting drying improves both quality and quantity of rice yield. Agron J 100:726-734

Zhu QH, Huang DY, Liu SL, Zhou B, Luo ZC, Zhu HH (2012) Floodingenhanced immobilization effect of sepiolite on cadmium in paddy soil. J Soils Sediments 12:169-177 